\title{
EVOLUCIÓN Y TENDENCIAS EN EL USO Y GESTIÓN TERRITORIAL DEL SISTEMA DUNAR DE GUARDAMAR Y ELCHE (ALICANTE)
}

\author{
José Manuel Giménez Ferrer
}

\section{RESUMEN}

El sistema dunar de Guardamar y Elche es, sin lugar a dudas, uno de los paisajes de mayor singularidad del litoral de la provincia de Alicante. Su peculiaridad se multiplica al analizar los rasgos de su constitución y evolución contemporánea, puesto que integra un enclave territorial donde sociedad y medio natural conforman las piezas básicas de un engranaje fácilmente alterable. El análisis-diagnóstico de la presión de usos que soporta ha de contemplar una serie de medidas que aseguren la supervivencia de un «espacio natural» clave en el devenir socioeconómico de los municipios en los que se integra.

Palabras clave: medio dunar, alteración natural, riesgos naturales, interacción hombre-medio e impactos territoriales.

\section{ABSTRACT}

The dunes of Guardamar and Elche is, clearly, one of the most peculiar landscapes of Alicante's coast. This peculiarity increases analyzing its features and contemporany evolution, to make up a territorial inclusion where society and environment are easily changeable. The analysis and diagnosis of the pressure of uses, that it suffers, bears an order of measures to secure the survival of a natural key space in the socioeconomic evolution of its township.

Key words: dunes, natural alteration, natural risks, the integration of man and its environment and territorial impacts.

\footnotetext{
* Becario de Proyecto de Investigación del Instituto Universitario de Geografía. Universidad de Alicante.
} 


\section{Interés del espacio geográfico de «las dunas de Guardamar y Elche»}

Las dunas de Guardamar y Elche forman un espacio de gran singularidad geográfica en las tierras alicantinas. De ubicación privilegiada, el territorio ocupado por las mismas se muestra como un inmenso vergel a orillas de un mediterráneo cuya «dulzura ambiental» queda ampliamente incrementada por la presencia de este singular paisaje. Bien es cierto que no constituyen un paisaje natural «sensu estricto», pero es ese factor sociocultural clave en su gestación lo que incrementa su valor geográfico.

Su singularidad e idiosincrasia territorial conforman a este enclave del mediterráneo español una serie de atractivos geográficos cuya conservación y preservación en el tiempo va estrechamente ligada al acervo cultural de las gentes que contribuyeron a su gestación. Su longevidad (su actual paisaje cuenta con apenas un siglo) no ha sido óbice para que en el mismo se hayan desarrollado, y desarrollen, una variada serie de acontecimientos que abarcan un gran número de espectros territoriales susceptibles de análisis geográfico.

En efecto, hace poco más de un siglo, se formó un medio hostil y de elevada peligrosidad natural ${ }^{1}$ motivada por una serie de interacciones entre la actividad humana y el medio geográfico preexistente. Gracias a dicha serie de relaciones, se incrementó sustancialmente la sedimentación de áridos hacia un cordón dunar que se extendía desde la parte más meridional del municipio de Santa Pola, hasta el norte del de Torrevieja; configurándose una situación de riesgo natural ${ }^{2}$ al confrontar las arenas móviles, con dirección a poniente, con el casco urbano y actividades económicas de Guardamar del Segura.

Este problema fue erradicado mediante una de las repoblaciones forestales más elogiadas de las que se han llevado a cabo en la provincia de Alicante. Gracias a ella, los municipios de Guardamar del Segura y, en menor medida, de Elche, Santa Pola y San Fulgencio; heredaron de la acción conjunta de sus ancestros y la naturaleza un paisaje que ha marcado su reciente evolución contemporánea; conocido el mismo como «Las dunas de Guardamar y Elche»o «El sistema dunar de Guardamar y Elche» ${ }^{3}$.

El análisis del espacio geográfico de las dunas de Guardamar y Elche ha de superar posicionamientos doctrinales tanto positivistas como deterministas, abogándo por aproximaciones caracterizadas por la interacción armónica entre sociedad y medio natural. Dentro de ese tipo de tesituras, se desea plasmar el presente escrito, mediante el cual no se busca más que incidir en la necesidad existente de llevar a cabo una correcta planificación de un medio cuya fragilidad es directamente proporcional a sus valores territoriales.

Tanto el análisis de los factores y elementos que explican su génesis y actual morfología, como la evaluación de su estado y perspectivas de futuro; constituyen pasos impres-

1 Concepto que hace referencia a las características ambientales de un determinado territorio, las cuales pueden ser peligrosas para la actividad humana; por tanto, existe peligrosidad natural en un espacio cuando en éste son frecuentes el desarrollo de uno, o varios, procesos ambientales extremos.

2 «Los riesgos naturales comprenden las manifestaciones de la naturaleza perjudiciales para el ecosistema humano» MATEU BELLES, J. (1993): Riesgos naturales y protección del medio ambiente en Geografía de España, (Méndez, R. y Molinero F., coords.). Editorial Síntesis. Barcelona, p. 255.

3 Nombres con los que se trabaja en los documentos de ordenación más importante realizados hasta la fecha para la totalidad de la unidad. «Anteproyecto de ordenación integral de las dunas de Guardamar y Elche. Provincia de Alicante. Comunidad Valenciana» (1997). Tragsatec-Consejería de Medio Ambiente de la Generalitat Valenciana; y GARCÍA DE LA RUIZ, J.R.; COPANO, C. y FERNÁNDEZ ESCALANTE, E. (1997): «Proyecto de restauración y consolidación del sistema dunar de Guardamar y Elche. Provincia de Alicante. Comunidad Valenciana». Tragsatec-Consejería de Medio Ambiente de la Generalitat Valenciana. Ambas denominaciones serán utilizadas indistintamente durante el presente escrito. 
cindibles que toda aproximación objetivada en valorar determinadas líneas de actuación ha de contemplar. Así, tras dicho análisis y diagnóstico derivado, se poseerá una serie destacada de elementos enjuiciables para emitir un conjunto de valoraciones territoriales siempre orientadas y encauzadas mediante el hilo conductor de toda la argumentación: la necesidad de preservar el paisaje de las dunas de Guardamar y Elche.

Como armazón imprescindible de la aproximación en estas líneas presentada, se acompañará el texto de una serie de fotografías, imágenes y mapas de contenido didáctico, tratando de favorecer con ello la claridad y rotundidad argumental con la que se trata de exponer la temática en cuestión.

Finalmente, no se pueden dejar pasar las siempre obligadas y merecidas reseñas a quienes, con su obra precedente, han ilustrado gran parte de los conocimientos que han derivado en las valoraciones que aquí se presentan. Esperemos que la referenciación de sus escritos en este modesto artículo sirva como humilde tributo de quien suscribe.

\section{Localización y contextualización del área de estudio}

El espacio geográfico objeto de atención se extiende a lo largo de una estrecha banda litoral ubicada en la parte más meridional de la provincia de Alicante, entre las salinas de La Mata (Torrevieja) y las del Pinet (Santa Pola). La configuración municipal del tramo costero donde éstas se desarrollan, propicia que sean cuatro los municipios que cuenten, en mayor o menor medida, con distintas partes de la superficie dunar objeto de atención. En concreto son, de sur a norte, Guardamar del Segura (636 Ha), San Fulgencio (11 Ha), Elche (131 Ha) y Santa Pola $(33 \mathrm{Ha})^{4}$. El sistema cuenta con una longitud inferior a los $13 \mathrm{~km} \mathrm{y}$ con una anchura que oscila entre 180 y 1.200 metros, con una altura máxima de los trenes de dunas de unos 23 metros $^{5}$.

Su morfología básica se plasma en la configuración de una playa, una duna litoral y una serie de trenes de dunas, repoblados de vegetación, con dirección predominante NW-SE, pudiéndose observar hasta cinco de estos trenes separados por angostos valles dunares.

Tal y como puede corroborarse en el mapa adjunto sobre la localización de la zona de estudio, es notorio el predominio de superficie dunar en los municipios de Guardamar del Segura y Elche, motivo el cual ha propiciado que sean éstos los que ostenten la denominación de la totalidad del presente cordón dunar (ver mapa 1).

\section{El paisaje de las dunas de Guardamar y Elche: elementos constitutivos}

\subsection{La alteración del equilibrio dunar preexistente}

Una vez definido el ámbito abarcado por el presente escrito, interesa introducirnos plenamente en la dinámica del individuo geomorfológico que fundamenta el sistema natural objeto de atención. Necesario es pues, comentar el origen y dinámica de un espacio dunar que, a principios de la presente centuria, «... se extendía a lo largo de 16 kilómetros, entre

4 Datos facilitados por estudiantes del tercer curso de biología de la Universidad de Alicante, a los cuales han sido suministrados por responsables en la realización del: «Proyecto de restauración y consolidación del sistema dunar de Guardamar y Elche. Provincia de Alicante. Comunidad Valenciana». Tragsatec-Consejería de medio ambiente de la Generalitat Valenciana. 1997.

5 ESCALANTE FERNÁNDEZ, E. (1998): Agentes y procesos que alteran el equilibrio dinámico del sistema dunar de Guardamar y Elche, en Alquibla: Revista de investigación del Bajo Segura; nº 4, pp. 441-461. 


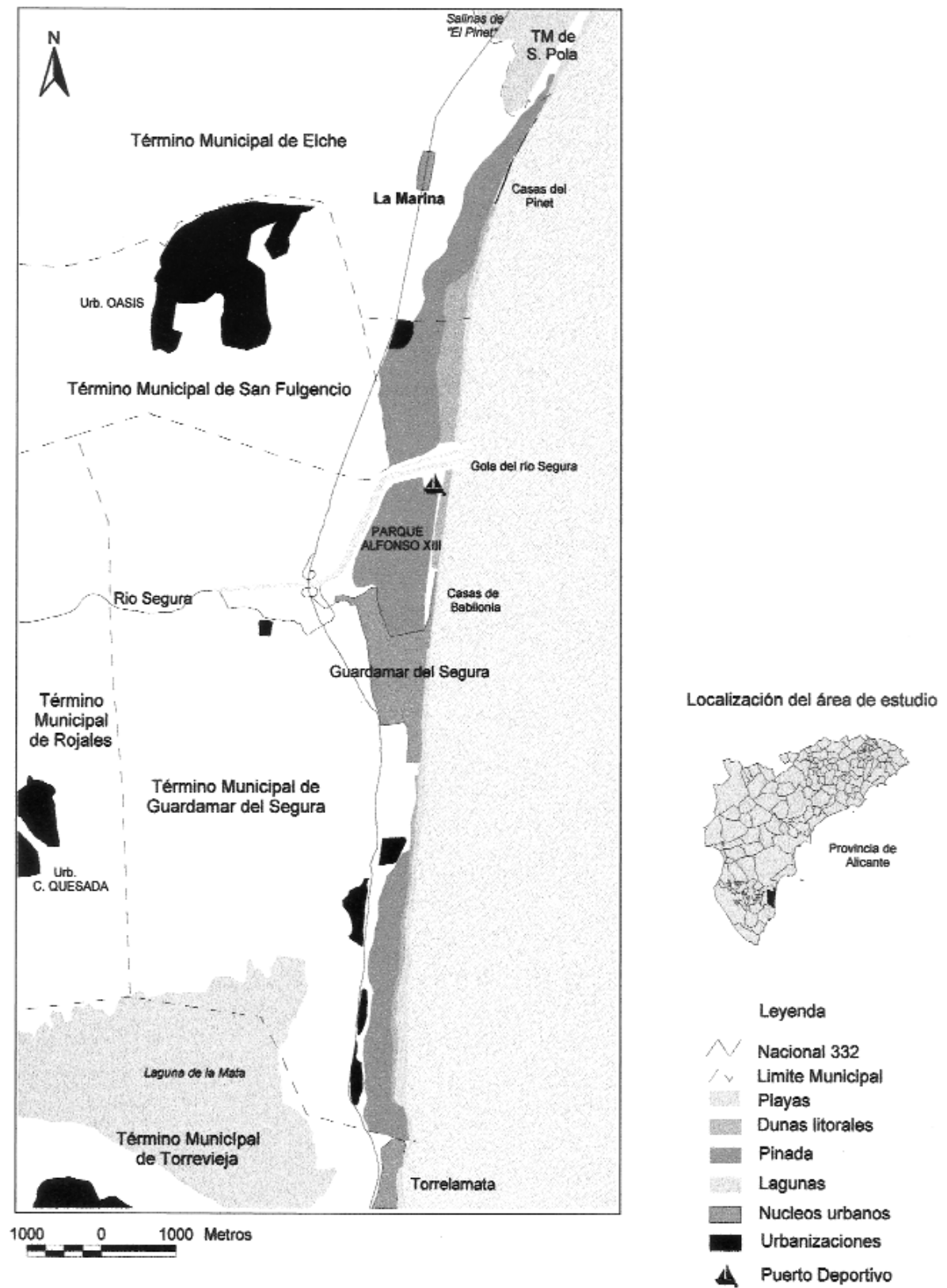

FuENTE: Elaboración propia a partir de la hoja 914 del Mapa topográfico Nacional (Servicio Geográfico del Ejército, 1997). Medios técnicos del Laboratorio de Sistemas de Información Geográfica y Cartografía Automatizada del Instituto Universitario de Geografía de la Universidad de Alicante.

MAPA 1. Localización y unidades constitutivas del «Sistema Dunar de Guardamar del Segura y Elche». 
el Cabo de Santa Pola y el de Cerver (Torrevieja), afectando a los términos de Guardamar del Segura y Elche. En el momento en que se iniciaron las tareas de repoblación, el término de Guardamar contaba con 673,50 hectáreas de formación dunar, ..., y el segundo, con 172,50 hectáreas» ${ }^{6}$.

Para entender los factores que propiciaron el incremento de una, ya preexistente, superficie dunar de origen cuaternario ${ }^{7}$, interesa investigar la interacción que se produjo entre distintos elementos del medio físico, así como las repercusiones que determinadas actuaciones antrópicas tuvieron en la dinámica del río Segura, colector éste clave en la configuración del espacio dunar que hoy se extiende, mayoritariamente, por el litoral de Guardamar del Segura y Elche.

Por lo que respecta a los orígenes de los aportes sedimentarios que fundamentan el sistema natural objeto de atención, dos son consideradas las fuentes primordiales de los mismos:

1. Imprescindible destacar la acción del eje fisiográfico vertebrador de la franja más meridional de la provincia de Alicante: el río Segura. La alteración antrópica que, a partir del siglo XVII, roturó y deforestó gran parte de sus cuencas alta y media, propició una seria alteración en la dinámica erosión-transporte-sedimentación del mismo. Esto incrementó la capacidad de ablación del colector con respecto a los márgenes de su cuenca, a lo que se unió la mayor deleznabilidad de una cuenca castigada por las constantes pérdidas de suelo derivadas de la reducción de cubierta vegetal. Este proceso favoreció el incremento de materiales sedimentados en desembocadura, con la consiguiente alteración del sistema natural hasta entonces imperante.

2. Se ha de reseñar, por otro lado, la existencia de un banco de areniscas blandas en el subsuelo de gran parte de la franja litoral de Guardamar del Segura y Elche. La dinámica marina se encargará de disgregar de forma continuada dicho substrato, poniendo a merced del oleaje, las corrientes y los vientos predominantes; una nada despreciable cantidad de aportes sedimentarios.

Una vez observada la creciente disponibilidad sedimentaria favorecida por la acción el río Segura y del banco de arenas sumergido, han de combinarse distintos factores para que estos materiales sean distribuidos sobre un antiguo cordón dunar de territorialidad mucho más reducida que la que pudo observarse a finales del siglo XIX. En lo que hace referencia a las arenas originadas por la disgregación del banco de areniscas blandas, éstas han tenido como agente de distribución básico la acción continua que sobre ellas ha ejercido el oleaje ordinario y el originado tras los temporales de levante. Su acción incansable y continuada sobre susodicho substrato, provocó la progresiva disgregación del mismo, distribuyéndose las arenas ya sueltas tierra adentro, ya que tal y como comenta M. Aldeguer: «...puede demostrarse fácilmente que la velocidad de avance de las partículas de agua, sobre todo después de romperse la órbita cíclica de la ola al tocar su parte inferior con el

6 MONTIEL MOLINA, C. (1990): «Los montes de utilidad pública en la provincia de Alicante». Editado por la Universidad de Alicante. Alicante, p. 191.

7 Para más información sobre los cordones dunares cuaternarios de la provincia de Alicante, ver el magnífico trabajo de ESCARRE, A.; MARTÍN, J. y SEVA, E.; —Eds. - (1989): «Estudio sobre el medio y la biocenosis de los arenales costeros de la provincia de Alicante». Editado por el Instituto de estudios Juan Gil-Albert de la Excma. Diputación Provincial de Alicante. Alicante, 129 pp. 
fondo, es muy superior a la de retroceso; lo cual supone una mayor capacidad de transporte hacia tierra $»^{8}$. Todo esto provoca la disgregación primero y, la distribución después, de las arenas hacia la superficie costera emergida.

Además de la acción continuada del oleaje, han de hacer su aparición otra serie de factores muy importantes en la definitiva distribución de las arenas hacia el interior de la franja costera de Guardamar del Segura y Elche. La existencia en el espacio comprendido entre el Cabo de Santa Pola y el de Cerver (Torrevieja) de una dinámica litoral de transporte meridiana y muy cercana a la línea de costa, constituye el marco ideal para que sobre ella actúen los flujos del E y SE predominantes en el presente ámbito; propiciando la distribución de los materiales con dirección W, NW y SW.

Así, de la combinación de oleaje, dinámica marina y vientos; pueden obtenerse los ítems básicos que facilitan la comprensión sobre los motivos que originaron el cordón dunar que hoy estructura el litoral más meridional de Elche y Santa Pola; así como la totalidad del de Guardamar del Segura. Sobre un substrato dunar, hoy fósil y de escasa importancia espacial, se superpuso otro de gran entidad superficial y de elevada movilidad originada por la agitada dinámica que propició la alteración del sistema natural que fundamentaba su origen. El incremento de aportes sedimentarios en desembocadura del río Segura registrados a partir del siglo XVII, justifica, en gran medida, el desmesurado crecimiento de unos arenales que, hasta hace unos 150 años, no se extendían más de unas decenas de metros tierra adentro 9 . La dinámica costera predominante vio así incrementados los aportes de áridos a redistribuir, cuyo reparto se llevó a cabo siguiendo los mismos patrones de siempre, pero algo había cambiado. Cambió que el equilibrio natural existente entre sedimentación fluvial y pérdida de materiales tras temporales quebró al incrementarse los aportes sólidos a distribuir por la dinámica costera. La ruptura de dicho equilibrio es la principal causante de la consolidación de un espacio dunar que creció más en dos siglos que en varios cientos de años. Prueba evidente de cómo la acción directa del hombre sobre un elemento del medio natural (tareas de deforestación y roturación en las cuencas alta y media del río Segura) puede traer consigo importantes alteraciones del medio, originando procesos nuevos o incrementando la dinámica de los existentes en un espacio relativamente alejado de la zona de intervención antrópica.

\subsection{La repoblación forestal de las dunas: la gestación de un nuevo paisaje}

Todo lo comentado con anterioridad nos remonta a finales de la pasada centuria, cuando los procesos descritos dieron origen a un cordón dunar litoral de extensión desconocidamente peligrosa para los moradores de los municipios a lo largo de los cuales éste se extendía. La dinámica dunar por entonces era imparable, manteniéndose el avance hacia poniente, poniendo en consiguiente peligro al casco urbano y actividades económicas de Guardamar del Segura (ver foto 1); siendo la peligrosidad prácticamente nula en el resto de municipios antes reseñados, al no existir asentamientos humanos ni actividades económicas de importancia en el espacio de avance de los arenales ubicado en los mismos.

\footnotetext{
8 ESCARRE, MARTÍN y SEVA, op. cit., 1989, p. 31.

9 MONTIEL MOLINA, C., op cit., 1990, p. 191; destaca que «... la aparición de aquellas formaciones de arena es relativamente reciente, ya que en 1829, cuando fue reconstruido el pueblo de Guardamar tras el terremoto de aquel año, las casas se edificaron a 800 metros de la línea de costa y, en aquella época los cultivos llegaban hasta pocos metros a la orilla del mar» (la autora extrae el fragmento subrayado de: «Crónica Forestal». Revista de Montes, 1907, $\mathrm{n}^{\circ} 739$, p. 644).
} 


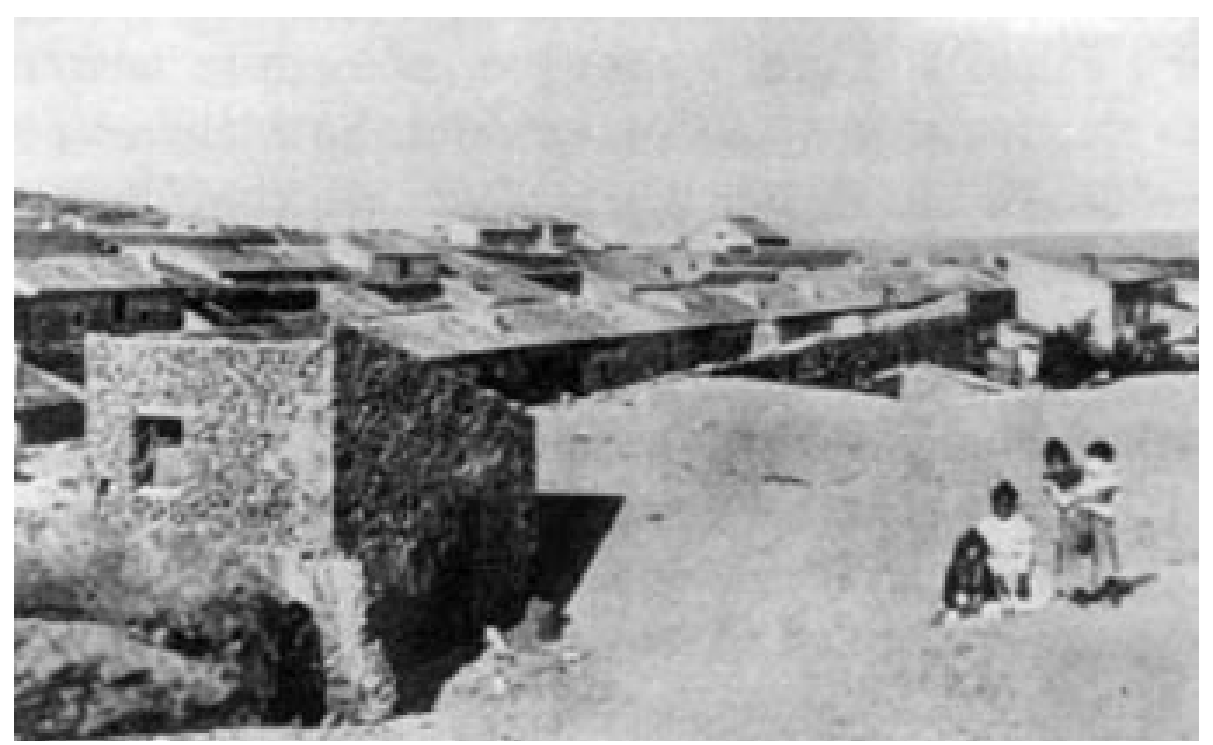

FOTO 1. Imagen de principios de siglo donde se manifiesta claramente el riesgo natural que las dunas suponían para el casco urbano de Guardamar del Segura. (FUENTE: ESCARRE, MARTÍN y SEVA, op. cit., 1989, p. 122).

Conforme las arenas fueron encontrando obstáculos en su trayectoria, se iban acumulando y desarrollando en función a los mismos, formando incipientes montículos con avances anuales que podían superar los ocho metros ${ }^{10}$; invadiendo progresivamente espacios de cultivo, hasta llegar a amenazar al casco urbano de Guardamar del Segura.

La situación comentada llevó a las autoridades competentes a valorar la necesidad de poner en práctica medidas para volver a salvar a un municipio que, pocos años atrás, había tenido que ser totalmente reconstruido ${ }^{11}$. Pese a que la fatalidad parecía haberse aliado con Guardamar del Segura, éste nunca terminará de agradecer la existencia de la misma. Esta afirmación viene motivada porque, a raíz de la situación de riesgo que la presencia de los arenales traía consigo, se llevó a cabo una de las repoblaciones forestales más laureadas de cuantas se han realizado en la provincia de Alicante $^{12}$. Dirigidas por el Ingeniero de Montes, D. Francisco Mira y Botella, comenzarán en 1900 los trabajos de repoblación y fijación de las arenas del municipio de Guardamar del Segura (al ser ésta la parte más afectada por

10 MONTIEL MOLINA, C., op. cit., 1990, p. 193.

11 Años atrás, Guardamar del Segura había sido totalmente destruido por el terremoto que asoló el Bajo Segura el 11 de marzo de 1829. No hubo reconstrucción, sino que se llevó a cabo una reedificación del poblado en las faldas del emplazamiento primigenio ubicado en el cerro del castillo. Este nuevo emplazamiento, lo ubicó en la que, pocos años después, sería la zona de avance de los reforzados arenales costeros, sin que éste suponga ningún tipo de protección contra posibles nuevos temblores de tierra. Como se dice popularmente, con su nuevo emplazamiento, Guardamar «salió de la sartén para meterse en las brasas». Para más información sobre dicho fenómeno sísmico y sus repercusiones, ver CANALES MARTÍNEZ, G. (dir.) y CALVO GARCÍA-TORNEL, F. (1999): «La catástrofe sísmica de 1829 y sus repercusiones». Editorial Pictografía. Murcia, 351 pp.

12 Importancia recogida en distintos artículos de la época sobre las tareas de repoblación, cuyo colofón radica en la visita que el Monarca Alfonso XIII realizó a dicha localidad con el fin de visitar las tareas de repoblación; ver: MONTIEL MOLINA, C., op. cit., 1990, p. 190. 
su avance), iniciándose a su vez, en 1907, en la margen izquierda del río Segura, incluyendo el resto de espacio de Guardamar y la totalidad del afectado en el municipio de Elche $^{13}$.

Sin entrar en pormenores sobre las características de la repoblación llevada a cabo, simplemente destacar que no es fácilmente evaluable lo que la misma ha supuesto. La repoblación de las dunas de Guardamar y Elche constituye un magnífico ejemplo ilustrativo de la actitud de una sociedad en una situación difícilmente extrapolable. La selección de dicha técnica operativa como fórmula de actuación, no sólo fue tan efectiva como brillante, sino que marca una forma de intervención territorial que, en este final de siglo donde la «sostenibilidad» se extiende como el término más socorrido en la ordenación y planificación del espacio geográfico, es difícilmente asimilable. Ante la posibilidad de actuar eliminando los arenales, se decidió repoblar, forzando la adaptación al medio de especies no climácicas al mismo, pero donde el esfuerzo de casi 30 años de trabajo dio un resultado hoy paisajísticamente admirado ${ }^{14}$.

Evidentemente, las dunas de Guardamar y Elche son fruto de una actuación humana con tintes épicos por la supervivencia de un pueblo, donde el esfuerzo del hombre ha tratado de compensar las nefastas actuaciones que en, cuencas alta y media del río Segura, fueron el origen de la problemática que obligó a repoblar los arenales de Guardamar y Elche. Parece que la sabia naturaleza ha querido jugar con el hombre, obligándole a subsanar, en los arenales de Guardamar y Elche, los impactos ambientales producidos en la cuenca del Segura.

\subsection{Unidades paisajísticas de las dunas de Guardamar y Elche}

Desde un punto de vista morfológico-paisajístico, el espacio hoy ocupado por las dunas de Guardamar y Elche puede segmentarse en una serie de unidades paisajísticas diferenciadas, pero a su vez estrechamente relacionadas entre sí en la configuración de la globalidad del espacio dunar preexistente.

Con dirección E-W, el espacio dunar objeto de atención puede diferenciarse en playa ${ }^{15}$, duna litoral y dunas repobladas. La diferenciación de la primera con respecto al resto radica en la reducida pendiente de las arenas que la conforman; así como en la ausencia de vegetación, sin existir ninguna otra de tipo morfológico. Tras ella, se extiende un cordón dunar litoral, interrumpiendo con brusquedad la morfología regular de la unidad anterior. Es fruto de las labores de consolidación de los arenales realizadas con anterioridad a la fijación vegetal de los mismos, siendo parte vital de la totalidad del sistema, actuando como redistribuidor de áridos hacia, y entre, el cordón dunar repoblado a poniente y la playa a levante. A continuación, pueden observarse los cordones de dunas repoblados, rompiendo bruscamente la homogeneidad de paisaje dunar prototípico que caracteriza a las dos unidades comentadas. Desde un punto de vista biogeográfico, destacar especies como el pino piñonero (P. pinea, L.), el pino carrasco (P. halepensis mill), la palmera común de fruto comestible (Phoenix dactylifera, L.), y los eucaluytus rostrata, gonphocefal y resinifera, así como

13 MONTIEL MOLINA, C., op. cit., 1990, p. 192.

14 Fruto de dichas labores de repoblación, los montes de dunas repoblados fueron propiedad de la administración forestal del Estado, hasta que el 15 de enero de 1985, ésta fue transferida a la administración ambiental de la Generalidad Velenciana. MONTIEL MOLINA, C., op. cit., 1990, p. 18.

15 Técnicamente, una playa es una franja con material movilizable, de topografía llana e irregular tendida hacia las aguas y debida a la acción del oleaje. DE PEDRAZA GUILSANZ, J. (1996). "Geomorfología. Principos, métodos y aplicaciones». Editorial Rueda. Madrid, p. 278. 
otras de porte arbustivo de importancia en la retención de arenas (Psamma arenaria, R.; Juncus communis, L. y Phragmites communis, trin).

Pese a las singularidades paisajísticas que definen a cada una de las tres unidades reseñadas, la interrelación entre las mismas es clave en la constitución de la totalidad de las dunas de Guardamar y Elche. En este sentido, es inconcebible la caracterización y ordenación de las mismas sin contemplar sus playas, su duna litoral y la pinada asociada a la repoblación antes comentada. La globalidad define la totalidad de un paisaje difícilmente concebible y planificable sin una de sus partes; sin ser esto óbice para que en las mismas se desarrollen distintos ecótopos muy poco diferenciados, al estar siempre sustentados sobre un substrato dunar que marca la morfología y fisiografía de la totalidad de las dunas de Guardamar y Elche ${ }^{16}$.

\section{Estado actual y perspectivas de futuro: agentes responsables en la dinámica dunar}

La presión litoral que define al paisaje de las dunas de Guardamar y Elche constituye uno de sus rasgos más significativos, a la vez que es, posiblemente, el factor de riesgo más acuciante para este singular espacio. Efectivamente, poco más se puede destacar sobre la «mágica» atracción territorial que el litoral ha ejercido sobre población y actividades antrópicas en este último siglo. Las implicaciones territoriales de este proceso pueden observarse atendiendo al ingente desarrollo de la actividad inmobiliaria, buscando situaciones privilegiadas enmarcadas en un contexto climático donde la benignidad térmica es la nota predominante.

El paisaje de las dunas de Guardamar y Elche no ha sido ajeno al desarrollo de nuevas actividades en el espacio. La presencia en las mismas de paisaje y playas constituye un privilegio territorial que no ha escapado a los ojos de la siempre omnipresente actividad turística-inmobiliaria, propiciando un consumo del espacio poco acorde con la conservación de los elementos que fundamentan el propio disfrute del territorio objeto de explotación turística.

La desafortunada ordenación del medio urbano, así como la dejadez y la permisividad administrativa en lo referente a la gestión y administración de las dunas de Guardamar y Elche ${ }^{17}$, no sólo han favorecido la reducción cuantitativa y cualitativa de las mismas; sino que, en algunos sectores, la merma (e incluso desaparición) de playa, duna litoral y pinada, constituye la dinámica predominante ${ }^{18}$.

Por todo ello, asistimos a un preocupante cambio en la concepción territorial del riesgo que las dunas de Guardamar y Elche constituyen para el medio geográfico. Hoy, los asentamientos y actividades económicas no están en peligro de desaparecer por el avance de los arenales, sino que son éstos los estrechamente amenazados por las actividades y asenta-

16 Es la merma cuantitativa y cualitativa de cualquiera de las tres unidades reseñadas a lo largo de la franja litoral que define a las dunas de Guardamar y Elche, el factor que determina el estado de conservación del espacio dunar.

17 Para más información sobre la urbanización del litoral alicantino, ver: VERA REBOLLO, J.F. (1987): «Turismo y urbanización en el litoral alicantino». Editado por el Instituto de Estudios Juan Gil-Albert de la Excma. Diputación Provincial de Alicante. Alicante, p. 357.

18 Hoy en día son muchos los sectores de los montes de dunas de Guardamar y Elche donde puede observarse la inexistencia de duna litoral (casco urbano de Guardamar y nuevos desarrollos del mismo; así como en la playa del Pinet en Elche), la pérdida de playas, y la reducción de la superficie forestal de las dunas (casco urbano de Guardamar y urbanizaciones Pórtico Mediterráneo, Dunas, Lomas del Polo y Pinomar y parte norte de la pedanía de la Marina en Elche). 
mientos humanos. Tanto la dejadez directa en la regeneración de las dunas por parte de las administraciones responsables, como las más brutales actuaciones urbanísticas con impacto directo en el medio dunar, conforman las más preocupantes coyunturas que afectan directamente a la supervivencia de las dunas de Guardamar y Elche.

Pero, a pesar de ser los predominantes y más preocupantes, no son sólo factores de origen antrópico los que inciden en la actual dinámica de las dunas de Guardamar y Elche. Otros de origen natural también son causa, y consecuencia a la vez, de su actual situación y de las implicaciones y posibles tendencias de la misma. A modo de conclusión, se presenta el cuadro adjunto sobre los principales agentes de incidencia en la dinámica de las dunas de Guardamar y Elche ${ }^{19}$. (ver cuadro 1).

\section{Análisis diagnóstico de aspectos territoriales de las dunas de Guardamar y Elche ${ }^{20}$}

Muy a pesar de lo razonablemente deseable las dunas de Guardamar y Elche no parecen gozar de la buena salud que una mayor dedicación a su conservación les otorgaría ${ }^{21}$. Son variados los aspectos que están provocando la consolidación de una serie de coyunturas cuya plasmación en el futuro no hacen más augurar negros auspicios para un territorio sin parangón. Criterios político-administrativos motivan que la gestión de las mismas no sea competencia única de un determinado departamento gubernamental; ya que tanto playas como duna litoral son gestionadas por la Dirección General de Costas, mientras que los montes de dunas repoblados son propiedad de la administración forestal regional (Conselleria de Medio Ambiente de la Generalidad Valenciana).

En un primer lugar, como principal enemigo del paisaje dunar, y muy en consonancia con las tendencias territoriales de buena parte del litoral de la provincia de Alicante, hemos de reflexionar sobre el modelo urbanístico propuesto por las autoridades municipales competentes y consentido por las autonómicas reguladoras de la competencia urbanística. En ese sentido, el crecimiento del casco urbano de Guardamar del Segura ha provocado la reducción de gran parte del espacio dunar que lo circundaba a levante, donde sus apéndices urbanísticos han provocado una merma en el mismo hoy imposible de recuperar ${ }^{22}$. Tampoco es loable denostar el crecimiento urbano en beneficio de la conservación a ultranza, pero tampoco son concebibles desarrollos urbanísticos desproporcionados en un medio donde sus características físicas marcan las diferencias cualitativas con el territorio circundante.

19 Extraído de las interesantísimas reflexiones realizadas por: ESCALANTE FERNÁNDEZ, E., op. cit., 1998 , pp. 441-461.

20 La importancia cuantitativa y cualitativa de este espacio en el municipio de Guardamar del Segura, provoca que gran parte de las valoraciones giren sobre la problemática detectada en este municipio. La incidencia territorial de las dunas en Santa Pola y San Fulgencio es mínima, pero tampoco se puede olvidar su impronta en el litoral de Elche, el cual, y salvo las casas en primera línea de la playa del Pinet, siempre ha mostrado una actitud proteccionista hacia el mismo digna de mención (lo cual se refunda con la línea de actuación seguida en su reciente PGMO aprobado en 1997).

21 Destacar, que en lo concerniente a agresiones al medio dunar, es en el municipio de Guardamar del Segura donde podemos hayar todo tipo de variados y ricos ejemplos ilustrativos del peligro al que está sometido un paisaje demasiado codiciado por la litoralidad que lo define.

22 Tal y como ya se ha comentado, en el momento en que se iniciaron las tareas de repoblación eran unas 673,5 las hectáreas existentes en Guardamar; mientras que hoy no son más de 636 Ha. El descenso en Elche es igual de ilustrativo: de 172,5 a 131 Has. Datos obtenidos de la comparación entre superficies existentes antes de iniciar las tareas de repoblación (MONTIEL MOLINA, ob. cit., 1990, p. 191) y las manejadas en el «Proyecto de restauración y consolidación del sistema dunar de Guardamar y Elche. Provincia de Alicante.», ob. cit., 1997. 
CUADro 1

Principales agentes y procesos morfogenéticos con influencia en el equilibrio dinámico del sistema dunar

\begin{tabular}{|c|c|c|c|c|c|}
\hline \multicolumn{2}{|c|}{ Agentes y procesos de origen natural } & \multicolumn{2}{|c|}{ Agentes y procesos de origen antrópico } & \multicolumn{2}{|c|}{ Agentes y procesos de origen mixto } \\
\hline Agente & Efectos & Agente & Efectos & Agente & Efectos \\
\hline \multirow[t]{2}{*}{ - Sequías. } & \multirow[t]{2}{*}{$\begin{array}{l}\text {-Deterioro de la vegetación. } \\
\text { - Aumento de la movilidad dunar. } \\
\text {-Disminución de aportes sedimentarios }\end{array}$} & $\begin{array}{l}\text { - Espigón de la } \\
\text { gola del Segura }\end{array}$ & $\begin{array}{l}\text {-Modificaciones locales en la dinámica } \\
\text { litoral, lo que puede modificar el sentido } \\
\text { del transpoote neto de las arenas. }\end{array}$ & \begin{tabular}{|l|} 
- Incisiones \\
trasversales en la \\
duna litoral.
\end{tabular} & $\begin{array}{l}\text {-La duna litoral supone la primera barrera de } \\
\text { contención de la arena mobilizada desde la playa, } \\
\text { y protege a la pinada, situada a poniente, de } \\
\text { temporales y de la incidencia del agente eólico. }\end{array}$ \\
\hline & & $\begin{array}{l}\text { - Encauzaminto del } \\
\text { Segura }\end{array}$ & $\begin{array}{l}\text { - Modificación de la zona de prodelta } \\
\text { comprendida entre la costa y la isla barrera, } \\
\text { anulando y mermando los vectores } \\
\text { bidireccionales de transporte de materiales } \\
\text { entre la gola y la línea de costa. }\end{array}$ & \begin{tabular}{|l} 
- Incisiones naturales. \\
.
\end{tabular} & $\begin{array}{l}\text {-Provocadas por la compartimentación } \\
\text { estructural de la zona. El compottamiento de } \\
\text { cada sector con respecto a dicha } \\
\text { compartimentacíón es desigual, incidiendo de } \\
\text { manera diferenciada en el avance de las dunas. }\end{array}$ \\
\hline \multirow[t]{5}{*}{ • Neotectónica. } & \multirow{5}{*}{ 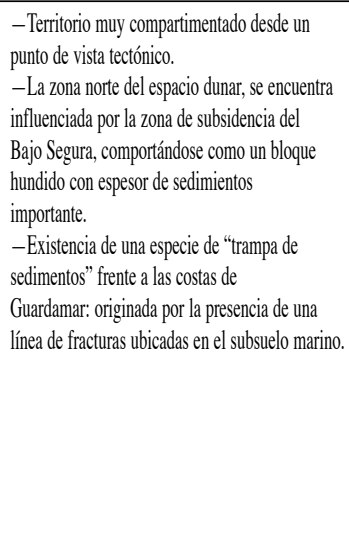 } & $\begin{array}{l}\text { • Regulación del } \\
\text { Seggura }\end{array}$ & $\begin{array}{l}\text {-Retención de sedimentos por los embalses } \\
\text { existentes en la cuenca. }\end{array}$ & $\begin{array}{l}\text { - Incisiones de origen } \\
\text { antrópico. }\end{array}$ & $\begin{array}{l}\text {-Incisiones originadas por el pisoteo y los } \\
\text { caminos creados por el hombre. } \\
\text {-Entrada de aire salino hacia la pinada por } \\
\text { dichas incisiones. Deterioro de la masa } \\
\text { forestal. }\end{array}$ \\
\hline & & $\begin{array}{l}\text {-Edificación en } \\
\text { primera línea de costa }\end{array}$ & $\begin{array}{l}\text {-Interrupción y ruptura del equilibrio en la } \\
\text { continuidad del sistema dunar. }\end{array}$ & & \\
\hline & & • Presión antrópica, & $\begin{array}{l}\text {-Merma de arenas por pisoteo, extracción y } \\
\text { tránsito rodado. }\end{array}$ & & \\
\hline & & - Acampadas & $\begin{array}{l}\text { - Incremento del pisoteo en los campings } \\
\text { ubicados en el propio cordón dunar. }\end{array}$ & & \\
\hline & & $\begin{array}{l}\text { 'Interdependencia } \\
\text { entre urbanización y } \\
\text { régimen de vientos }\end{array}$ & $\begin{array}{l}\text {-Modificaciones en la dirección de los flujos } \\
\text { predominantes por la incidencia de las } \\
\text { edificaciones en la primera línea de costa. }\end{array}$ & & \\
\hline • Dinámica litoral. & $\begin{array}{l}\text {-Incidencia directa de todo tipo de variaciones } \\
\text { en la dirección de las corrientes (meridiana } \\
\text { predominantemente) y la de los flujos asociados. }\end{array}$ & & & & \\
\hline
\end{tabular}


Del desarrollo urbanístico pasado, amparado en legislaciones y tendencias territoriales irremediablemente vinculadas al crecimiento rápido de la actividad económica, hay que señalar que éste se basó en concesiones administrativas sobre el espacio dunar, alterando irremediablemente el equilibrio conseguido años atrás (planes parciales Dunas de Guardamar, Lomas del Polo y casas de Babilonia en Guardamar; así como las casas de la playa del Pinet en Elche). Estas actuaciones se sustentaron sobre el espacio dunar, multiplicando en superficie al plano primigenio de Guardamar del Segura puesto en práctica por D. José Agustín Larramendi tras el seismo de 1829. Pero es en los desarrollos amparados en la era de la «sostenibilidad»sobre los que es necesario reflexionar. En efecto, bajo los auspicios de un aparato normativo eminentemente proteccionista, siguen siendo frecuentes las agresiones urbanísticas a un medio supuestamente protegido por ley, al pertenecer al patrimonio forestal de la Comunidad Autónoma Valenciana. El modelo urbanístico propuesto por las autoridades locales del municipio de Guardamar aboga por un crecimiento lineal hacia el sur, hasta unir el actual casco urbano con el hotel Campomar (ubicado junto a la urbanización Pórtico Mediterráneo), consolidando un modelo de desarrollo lineal poco acorde con la conservación de su litoral ${ }^{23}$. Otro tanto se puede decir sobre el conocido como SUP7 ${ }^{24}$, donde ya desde hace años se espera la edificación en altura colindante con la pinada de Guardamar del Segura; actuación totalmente inadecuada desde un punto de vista paisajístico.

Mención aparte merece el puerto deportivo Marina de las Dunas y el centro de ocio y residencia asociado al mismo. Ubicado en el límite septentrional del Parque Alfonso XIII, junto a la actual desembocadura del río Segura, puede que el desarrollo de esta infraestructura y las actuaciones derivadas, marque inexorablemente el devenir urbanístico de Guardamar del Segura y el futuro paisaje del espacio dunar de dicho municipio. En primer lugar, el Parque Alfonso XIII, constituye la porción de dunas repobladas más presionadas de todo el cordón dunar de Guardamar y Elche, estando circunscrita por el casco urbano de Guardamar del Segura y el río Segura. Mediante la figura de Parque Urbano, el consistorio de Guardamar del Segura ha logrado potestad en la gestión de esta parte del espacio dunar, consiguiendo desarrollar un puerto deportivo en una zona donde pros y contras van estrechamente cogidos de la mano. Por desgracia, la puesta en marcha de dicha instalación portuaria, no ha sido realizada tal y como podía haber sido deseable en aras de la conservación y protección del espacio dunar circundante. Los accesos al mismo se realizan a través del Parque Alfonso XIII, previéndose para el estío de 1999 (el primero con el puerto operativo) una multiplicación del ya importante volumen de vehículos a atravesar el espacio dunar. Por desgracia, la inoperancia en la gestión de los sistemas de acceso al puerto por la parte norte de Guardamar sin castigar a la zona dunar, marcan el devenir inmediato del Parque Alfonso XIII ${ }^{25}$.

23 Todo ello subyace en la actual revisión que desde el consistorio municipal se está abordando del vigente PGOU de 1985. Tanto lo determinado en los planos de clasificación propuestos, como por las declaraciones de miembros del gobierno en la televisión pública de Guardamar, no hacen más que constatar dicho modelo de crecimiento.

24 Espacio ubicado entre el río Segura y el casco norte de Guardamar del Segura, lindando con el extremo más noroccidental del Parque Alfonso XIII.

25 Los accesos previstos al puerto pasan por el desarrollo del SUP7, hoy paralizado por falta de acuerdo entre el ayuntamiento y los propietarios del suelo. Mientras dure el litigio, el puerto seguirá sin contar con un acceso que no convierta al Parque Alfonso XIII en una auténtica vía de circulación urbana. 


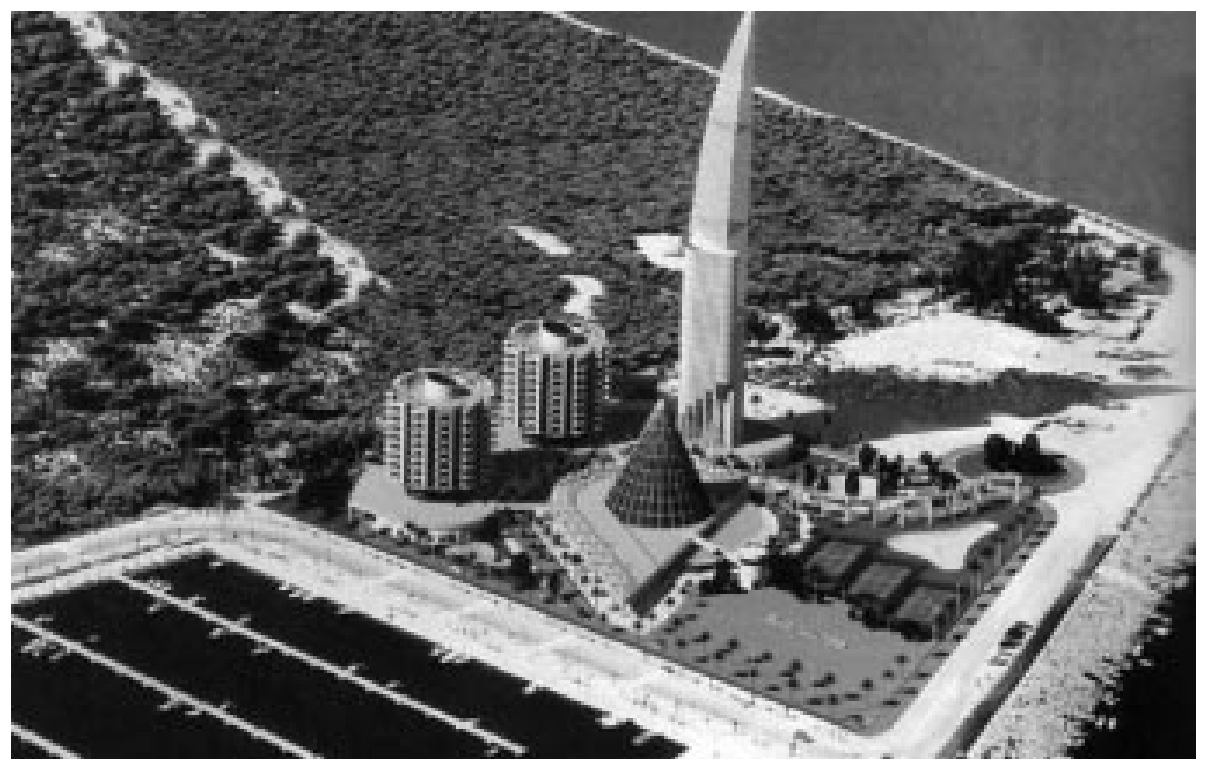

Fото 2. Apréciese el impacto territorial de una de las zonas de ocio propuestas para desarrollar económicamente el puerto deportivo y aledaños. Si actuaciones de este tipo consiguen desarrollarse (y la renovada alcaldía del principal partido defensor de la misma parece augurarlo), la ruptura de la morfología paisajística del municipio será manifiesta e irreversible. (FUENTE: «Programa de gobierno del Partido Popular para el Ayuntamiento de Guardamar del Segura» 1999).

Pero no son sólo los accesos al puerto el principal problema, sino las actuaciones previstas para consolidar a la zona del mismo como un centro turístico de características únicas en la Costa Blanca. Son varias las propuestas manejadas en el consistorio municipal para ejecutar, en el linde septentrional del Parque Alfonso XIII, junto al puerto, un macrocomplejo lúdico donde, si destacará algo, será la magnitud de los inmuebles a construir. Bloques de hormigón comparables a los existentes en Benidorm ${ }^{26}$, forman parte del complejo para «revalorizar y recualificar al municipio de Guardamar». El impacto paisajístico de dicha actuación es inimaginable, y la aberración urbanística, desde un punto de vista territorial, será difícilmente igualable en todo el litoral mediterráneo (ver foto 2).

A la vista de las actuaciones aprobadas y previstas que tienen por espacio este singular paisaje, es de reseñar la necesaria preservación del amenazado territorio que ocupan las dunas de Guardamar y Elche, utilizando las figuras de protección municipal que la legislación del suelo ofrece a tal efecto. Territorialmente sería exigible que se mantenga la clasificación de todo el espacio ocupado por la pinada como suelo no urbanizable de especial protección, gracias a los valores ecológicos y paisajísticos del territorio en cuestión. Pero la historia reciente nos muestra que no sólo basta con ello, siendo incluso recomendable establecer bandas de protección para evitar la presión que un cinturón urbano provoca en

26 Ni mucho menos ha de concebirse la comparación como una crítica al actual modelo urbanístico de Benidorm, el cual, personalmente, es tan admirado como apreciado. Pero cada cosa en su sitio; ni los rascacielos ni los grandes bloques de apartamentos encajan ni encajarán nunca en Guardamar del Segura. 


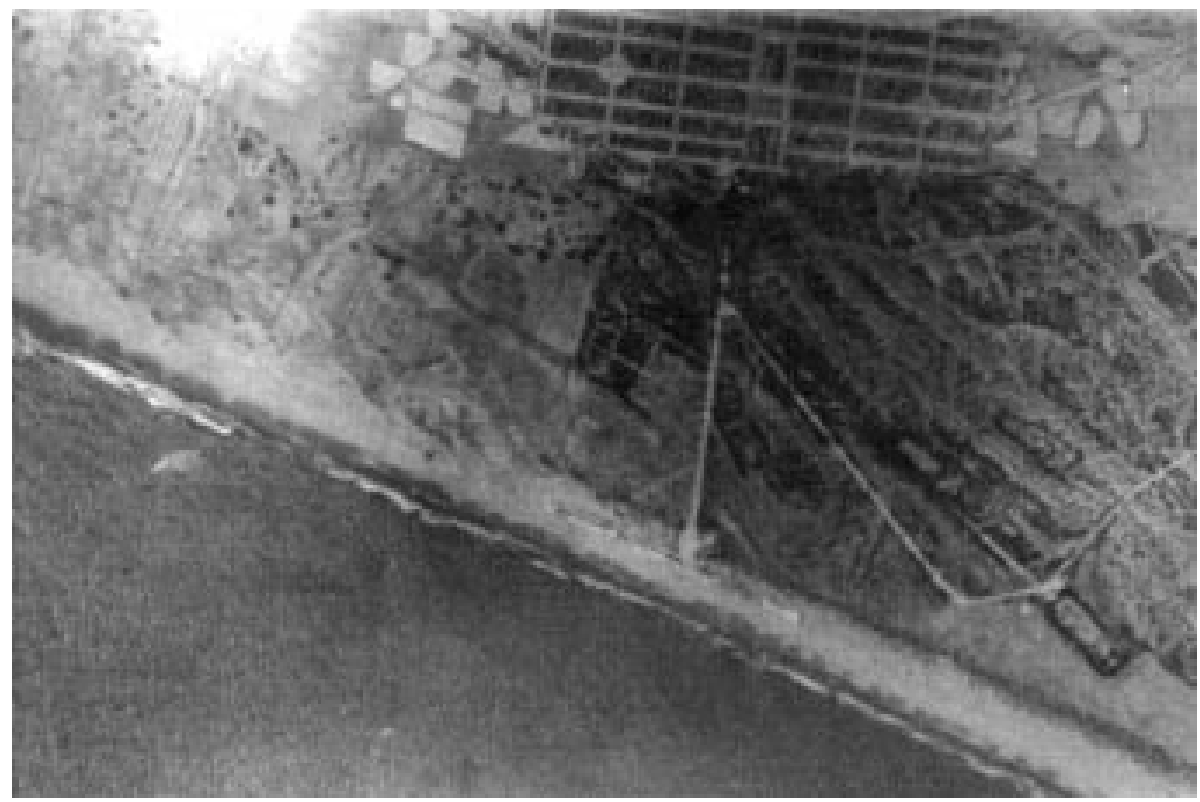

Fото 3. Vista aérea de Guardamar del Segura en el año 1956. La magnitud de los cordones de dunas es lo predominante en el paisaje costero de dicho municipio. (FUENTE: «Anteproyecto de ordenación integral de las dunas de Guardamar y Elche. Provincia de Alicante. Comunidad Valenciana» ob. cit., 1997).

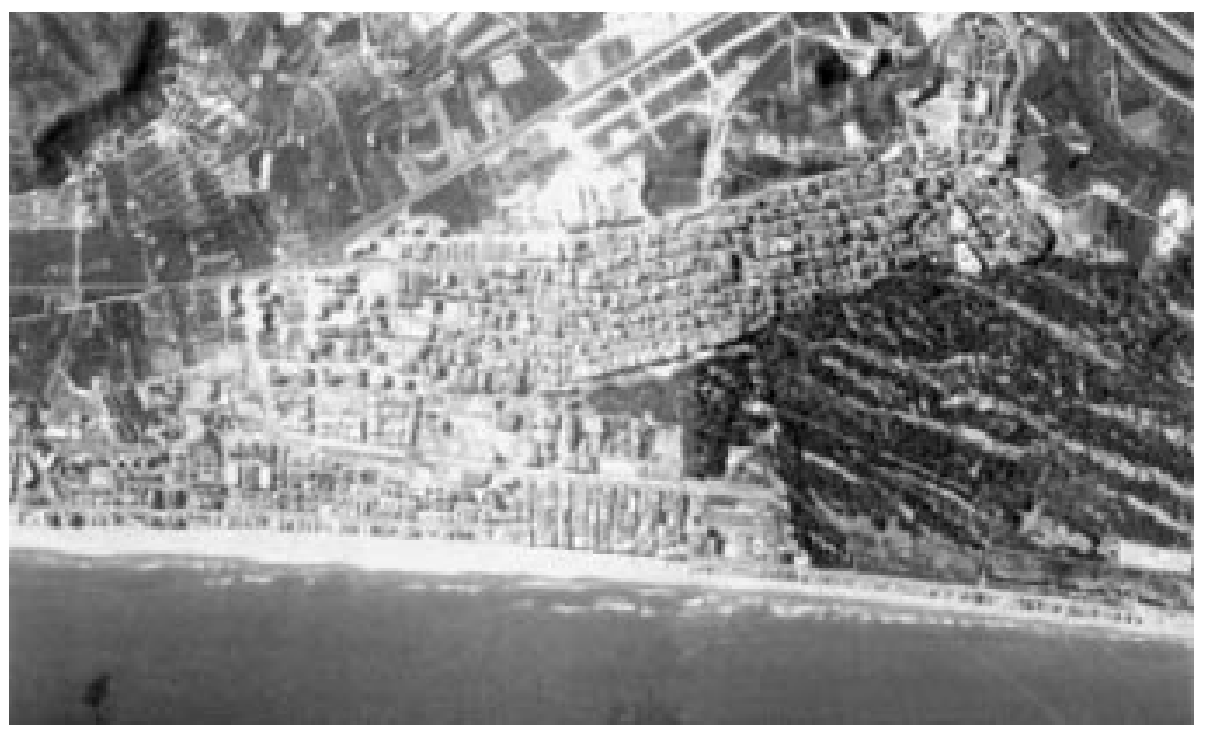

Fото 4. Casco urbano de Guardamar del Segura en 1997. Se aprecian los importantes cambios en el uso del suelo acaecidos hasta fecha de hoy. (FUENTE: «Anteproyecto de ordenación integral de las dunas de Guardamar y Elche. Provincia de Alicante. Comunidad Valenciana» ob. cit., 1997). 
todo espacio protegido ${ }^{27}$. Evidentemente, las playas y la duna litoral no pueden tocarse en los sectores donde existen, al estar estrictamente protegidas por la legislación de costas, pero si es necesario contemplar su conservación en todo tipo de actuaciones que puedan afectar a la dinámica que alimenta y sustenta de áridos a la costa de Guardamar del Segura (ver fotos 3 y 4 sobre el cambio acontecido en los usos del suelo en parte del litoral de Guardamar del Segura).

Otro punto a tratar es el estado de degradación de gran parte de la masa forestal que caracteriza a las dunas de Guardamar y Elche, derivado éste del paso de los años en unas especies no climácicas a un substrato tan complejo como el dunar. Este hecho ha propiciado que la autoridad responsable en su gestión tome cartas en el asunto. Si hace un siglo era el casco urbano y las actividades económicas del municipio de Guardamar las que estaban en peligro por el avance dunar, hoy es el espacio originado tras la repoblación el que presenta un riesgo grave de degradación por la propia presión humana directa y por la no-ejecución de medidas eficaces de regeneración y mejora de la superficie forestal.

En este último sentido, la Consellería de Medio Ambiente de la Generalidad Valenciana está realizando los estudios previos para poner en práctica un proyecto de ordenación integral de los montes de dunas de Guardamar y Elche. Este estudio busca derivar en la puesta en práctica de medidas para regenerar la masa forestal y adecuar, aún más, al uso público el espacio dunar existente. De los más de 600.000 árboles utilizados para la repoblación, se calcula que en la actualidad quedan unos 250.000 , sufriendo todo el sistema dunar de Guardamar y Elche una presión humana cifrada en unas 500.000 personas al año. La degradación y merma en su masa forestal, está provocando que las arenas vuelvan a retomar su dinámica natural, progresando en algunos puntos sondeados (aparcamiento central del Parque Alfonso XIII) hasta 5 metros anuales ${ }^{28}$. La necesidad de actuar en la regeneración de la masa forestal es absolutamente evidente, no sólo desde un punto de vista paisajístico y conservacionista, sino también para evitar que, de nuevo, el avance de las arenas ponga en peligro a los asentamientos y actividades económicas de los municipios afectados.

A pesar de la necesidad de un eficaz proyecto de regeneración y planificación del espacio dunar, hasta fecha de hoy apenas se han llevado a curso actuaciones enmarcadas en el proyecto gubernamental antes aludido. No obstante, éste tampoco parece ser la gran solución para acabar con gran parte de los problemas de degradación y congestión que sufren hoy en día las dunas de Guardamar y Elche; ya que gran parte de las actuaciones previstas van a incrementar de manera brutal la presión pública sobre el espacio dunar (en concreto sobre el más explotado de todos ellos: el Parque Alfonso XIII) mediante la mejora de los accesos, la creación de aparcamientos dentro del parque y una poco afortunada actuación sobre la duna litoral, proponiendo pasos peatonales hacia la playa que cortan transversalmente la propia duna ${ }^{29}$.

27 Los vigentes PGMO de los municipios más implicados en su dinámica (Guardamar y Santa Pola, 1985 y Elche, 1997) son los principales responsables de dotar al municipio de políticas territoriales comprometidas con la conservación de los cordones dunares. No basta con la mera (e impuesta) clasificación como suelo no urbanizable, sino que ésta ha de ir acompañada de una comprometida política de protección y revalorización acorde con su conservación, pero nunca en su promoción territorial de cara a la revalorización inmobiliaria de un entorno quizás ya excesivamente saturado.

28 Diario INFORMACIÓN: 6-12-98.

29 Ello puede observarse a la perfección consultando el «Anteproyecto de ordenación integral de las dunas de Guardamar y Elche. Provincia de Alicante. Comunidad Valenciana». ob. cit., 1997. 


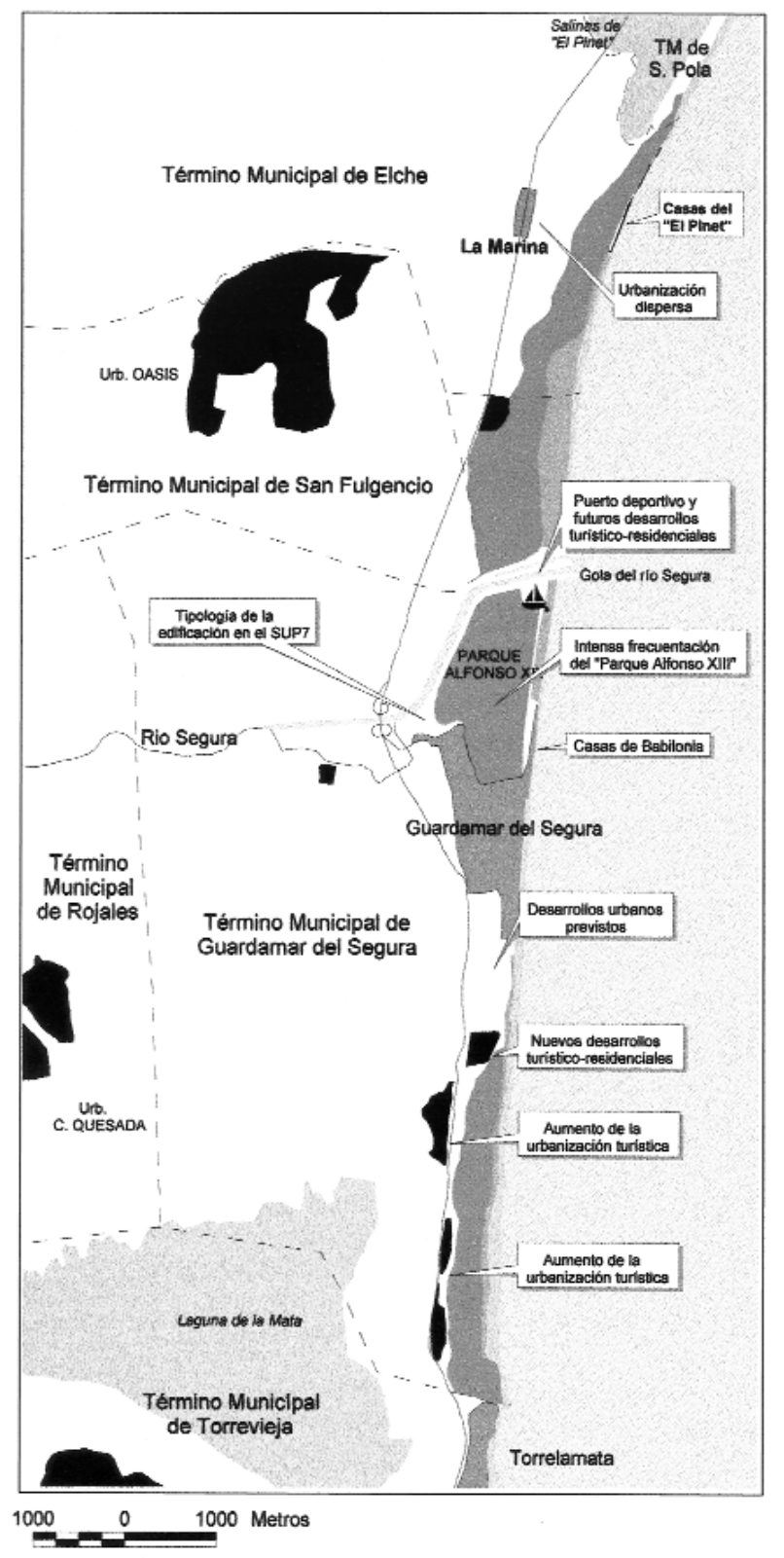

Localización del área de estudio

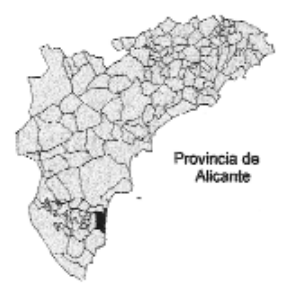

Leyenda

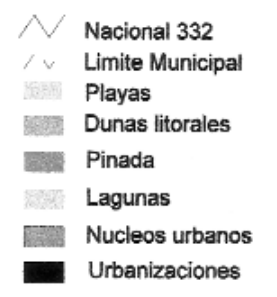

A Puerto Deportivo

FuENTE: Elaboración propia a partir de la hoja 914 del Mapa topográfico Nacional (Servicio Geográfico del Ejército, 1997). Medios técnicos del Laboratorio de Sistemas de Información Geográfica y Cartografía Automatizada del Instituto Universitario de Geografía de la Universidad de Alicante.

MAPA 2. Principales impactos al «Sistema Dunar de Guardamar del Segura y Elche». 
Así, la presión actual que sufre la totalidad del paisaje dunar es considerable, y más aún preocupante, si se valoran detenidamente las actuaciones propuestas para su regeneración. La conservación de la totalidad de los más de diez kilómetros de trenes de dunas repoblados exige, con la mayor brevedad, la regeneración de la cubierta vegetal; así como estudios encauzados a determinar su capacidad de carga, a la reducción del tráfico rodado en su interior, a la construcción, de manera integrada con el paisaje, de zonas aptas para el uso público (evitando así la dispersión de los visitantes por zonas frágiles del espacio dunar) y a frenar las concesiones de edificación en el propio espacio dunar y en un margen de protección preestablecido a tal efecto. Sólo así compatibilizaremos su disfrute con su conservación forestal y con la detención del nuevo avance de las arenas detectado.

Para la correcta planificación de este complejo litoral, han de imponerse metodologías donde la pluridisciplinaridad sea el hilo conductor de las mismas; más si cabe si nos enfrentamos ante la ordenación, necesariamente integral, de un espacio donde concurren competencialmente dos administraciones y un complejo entramado de elementos territoriales a sopesar y donde impactos y agresiones pasadas conviven con la amenaza de futuras intervenciones de elevada problemática para el medio dunar de Guardamar del Segura y Elche (ver mapa 2).

\section{Conclusiones. La necesidad de conservar este singular ecosistema}

A pesar del estado de degradación comentado con respecto a su situación décadas atrás, el valor de este amplio cordón dunar es hoy, incuestionable. En 1982, y con objeto de inventariar los espacios de mayor calidad ambiental de la Nación española, el Centro de Estudios para la Ordenación del Territorio y Medio Ambiente (CEOTMA), elaboró una relación de zonas costeras que requieren una protección especial con carácter Nacional, donde sólo las dunas de Guardamar y Elche fueron citadas entre todo el litoral alicantino:

«Dunas de Guardamar y Elche: duna litoral situada a ambos lados de la desembocadura del río Segura; de interés paisajístico por las masas de pinos que la pueblan y que ofrecen inmejorables condiciones para su uso recreativo. Superficie actual: $774 \mathrm{Ha}$; Amenazas: demanda urbanística intensa, peligro de incendios y deterioro ambiental por la gran presión a la que está sujeta» ${ }^{30}$.

De la consideración existente en el ámbito nacional de este espacio, desprendida tras la lectura precedente, es destacable, a nuestro modesto entender, la insuficiente protección existente en la actualidad para el mismo. La Generalidad Valenciana, propietaria de las dunas repobladas, impone la clasificación de su suelo (en el planeamiento de los municipios que las contienen) como SNU de Especial Protección, a excepción del espacio dunar que constituye el Parque Alfonso XIII (tal y como hemos comentado, el sector dunar más intensamente presionado), que goza de la curiosa clasificación legal de «Parque Urbano». A través de estas líneas sería interesante reflexionar en voz alta por qué las dunas de Guardamar y Elche no gozan de ninguna figura protección dentro del marco establecido por la Ley 11/94, de 27 de diciembre, de Espacios Naturales Protegidos de la Comunidad Valen-

30 CEOTMA, 1982; citado por TORRES ALFOSEA, F.J. (1997): «Ordenación del litoral en la Costa Blanca». Editado por la Universidad de Alicante. Alicante, p. 122. 
ciana. Pocos espacios de nuestra comunidad ejemplifican tan bien la configuración de un ecosistema único gracias a la acción del hombre, con unos fines conservacionistas y proteccionistas dignos de todo elogio por la época en la que las actuaciones se llevaron a cabo. Bien es cierto que no es un espacio natural «sensu estricto» pero las condiciones de su formación son extraordinariamente indicativas del interés de la sociedad de la época por la protección y conservación del territorio, configurando con todo ello un espacio donde el paisaje dunar emerge con unos condicionantes únicos en todo el litoral mediterráneo español. Si las dunas de Guardamar y Elche no constituyen en el ámbito regional un «área o hito geográfico que contenga elementos o sistemas naturales de particular valor, interés o singularidad, tanto debido a la acción y evolución de la naturaleza, como derivados de la actividad humana...» ${ }^{31}$, se desconoce cual será el aspecto que determine dicha carencia.

Así, de las siete figuras de protección amparadas en dicha ley, son perfectamente extrapolables a las dunas de Guardamar y Elche:

Artículo noveno. Parajes naturales municipales. Constituirán parajes naturales municipales las zonas comprendidas en uno o varios términos municipales que presenten especiales valores naturales de interés local que requieran su protección, conservación y mejora y sean declaradas como tales a instancia de las entidades locales.

Artículo catorce. Paisajes protegidos. Los paisajes protegidos son espacios, tanto naturales como transformados, merecedores de una protección especial, bien como ejemplo significativo de una relación armoniosa entre el hombre y el medio natural, o bien por sus especiales valores estéticos o culturales ${ }^{32}$.

Es sobre todo en esta última figura, donde la situación de las dunas de Guardamar y Elche queda, tan perfectamente enmarcada, que la misma parece haberse articulado para acoger a este espacio. Su declaración como espacio natural protegido facilitaría su gestión mediante la creación de un organismo para tal fin, así como determinaría el estado de los recursos naturales y planificaría su utilización, disfrute y explotación mediante una estricta zonificación; sin olvidar en ningún momento la asignación de presupuestos anuales para su funcionamiento y conservación. Además, se ha de destacar que su propia titularidad pública constituye una de las principales ventajas para proceder a tramitar su declaración, evitándose las gravosas compras y las siempre problemáticas expropiaciones. Finalmente, y para ponerlo aún más sencillo, la encargada de iniciar los trámites para la protección de un espacio es la propia Consellería de Medio Ambiente ${ }^{33}$; la cual es la propietaria del espacio de dunas repobladas del cordón dunar de Guardamar y Elche ${ }^{34}$.

En apretado balance, se considera que este singular espacio ha de ser conservado y mejorado (mediante la aplicación de planes y de las figuras legales que se estimen oportunas) por cuatro razones básicas:

31 Artículo 1.3 de la Ley 11/94, de 27 diciembre, de espacios naturales protegidos de la Comunidad Valenciana.

32 La negrita es nuestra.

33 Artículo 29.1 de la Ley 11/94, de 27 de diciembre, de espacios naturales protegidos de la Comunidad Valenciana.

34 Un acuerdo entre las dos administraciones involucradas en su gestión, en aras de consolidar definitivamente una definición de objetivos, sería el primer paso en la consolidación de una nueva era para este singular paisaje. 
1. Históricas: las dunas y su repoblación constituyen una importante porción del devenir contemporáneo de los municipios que las contienen, destacando sobremanera su importancia en Guardamar del Segura.

2. Sociales: la repoblación llevada a cabo con el fin de frenar el avance de las arenas, es el mejor exponente de la actitud de un pueblo ante una situación de difícil solución. A dicha actitud ante el territorio, se debe que, en la actualidad, moradores y visitantes disfruten activamente de este entorno mediante la evasión y el esparcimiento de sus quehaceres cotidianos.

3. Ecológico-paisajísticas: además de la magnitud y singularidad que constituyen las dunas de Guardamar y Elche como individuo geomorfológico, la repoblación forestal llevada a cabo sobre ellas ha configurado un espacio de valores ecológicos, paisajísticos y científicos difícilmente mejorables en nuestro litoral provincial.

4. Económicas: el espacio dunar ubicado en el litoral de Guardamar del Segura y Elche, constituye el principal atractivo cualificador de su oferta turística. Las nuevas tendencias imperantes en los comportamientos del turista giran hacia la búsqueda de entornos donde la calidad ambiental y del paisaje son aspectos tremendamente valorados en la elección de un destino. La conservación y explotación racional de este elemento es pieza clave para la consolidación de Guardamar del Segura y Elche como municipios turísticos con personalidad propia dentro de un entorno excesivamente sobreexplotado.

La administración responsable de su acertada y meritoria creación es, en la actualidad, la máxima garante en su conservación y gestión. A ella tendremos todos que exigir fulminantes responsabilidades si la incompetencia, el desconocimiento y la dejadez condenan a este espacio a su desaparición. Además de criterios históricos, sociales, ecológicos y paisajísticos; el cordón dunar de Guardamar y Elche es el principal agente cualificador de su espacio litoral en detrimento del circundante. Para convertirse Guardamar del Segura en un municipio turístico saturado y degradado desde un punto de vista medioambiental, sólo media la desaparición y degradación de las arenas y su masa forestal. El sistema dunar de Guardamar y Elche, y en concreto la porción de Guardamar del Segura, constituye el elemento diferenciador del municipio con respecto al resto, así como el espacio más valorado del mismo desde un punto de vista territorial. Estas premisas hacen obligada su conservación y revalorización como agente revitalizador y protagonista en la dinámica socioeconómica de Guardamar del Segura y de la franja más meridional del litoral de Elche.

No es fácil sobrevivir en un medio donde la presión inmobiliaria es enorme, con generación de enormes plusvalías inmediatas, pero hipotecando un futuro que evoluciona hacia el rechazo de los entornos ambientalmente degradados y territorialmente impersonales. Sólo admitiendo el riesgo existente es posible la planificación y puesta en práctica de eficaces medidas que comprometan a todos los estamentos públicos y privados de incidencia en su preservación. La conservación equilibrada y racional de su función social es la clave para que el factor riesgo se estabilice de una vez por todas, sin que las dunas pongan en peligro al hombre ni viceversa. Cuando esto se logre, el hombre se habrá introducido de forma activa y beneficiosa en el sistema natural que caracteriza a esta singular porción del sur de la provincia de Alicante. 


\section{Bibliografía y fuentes consultadas}

«Anteproyecto de ordenación integral de las dunas de Guardamar y Elche. Provincia de Alicante. Comunidad Valenciana» (1997). Tragsatec-Consejería de Medio Ambiente de la Generalitat Valenciana. Valencia, 14 pp.

CANALES, MARTÍNEZ, G. - Dir. - (1995): «El Bajo Segura: estructura espacial, demográfica y económica». Editado por la Fundación Cultural CAM y la Universidad de Alicante. Alicante, 312 pp.

CANALES MARTÍNEZ, G. - Dir. - y CALVO GARCÍA-TORNEL, F. (1999): «La catástrofe sísmica de 1829 y sus repercusiones». Editorial Pictografía. Murcia, 351 pp.

ESCARRE, E.; MARTÍN, J. y SEVA, E.; —Eds. - (1989): «Estudios sobre el medio y la biocenosis de los arenales costeros de la provincia de Alicante». Editado por el Instituto de Estudios Juan Gil-Albert de la Excma. Diputación Provincial de Alicante. Alicante, $129 \mathrm{pp}$.

ESCALANTE FERNÁNDEZ, E. (1998): «Agentes y procesos que alteran el equilibrio dinámico del sistema dunar de Guardamar y Elche». Alquibla: Revista de investigación del Bajo Segura; $\mathrm{n}^{\circ}$ 4, 720 pp.

DE PEDRAZA GILSÁN, J. (1996): «Geomorfología. Principios, métodos y aplicaciones». Editorial Rueda. Madrid, 414 pp.

MÉNDEZ, R. y MOLINERO, F.: - Directs. - (1993): «Geografía de España». Editorial Ariel. Barcelona, 759 pp.

MONTIEL MOLINA, C. (1990): «Los montes de utilidad pública de la provincia de Alicante». Editado por la Universidad de Alicante. Alicante, $227 \mathrm{pp}$.

TORRES ALFOSEA, F.J. (1997): «Ordenación del litoral en la Costa Blanca». Editado por la Universidad de Alicante. Alicante, $269 \mathrm{pp}$.

VERA REBOLLO, J.F. (1987): «Turismo y urbanización en el litoral alicantino». Editado por el Instituto de Estudios Juan Gil-Albert de la Excma. Diputación Provincial de Alicante. Alicante, $431 \mathrm{pp}$.

VV.AA. (1997): «Guía ciudadana de los riesgos geológicos». Editado por el Ilustre Colegio Oficial de Geólogos de España. Madrid, 196 pp.

VV.AA. (1997): «Aereoguía del litoral de Alicante y Murcia». Editado por Editorial Planeta, S.A. Barcelona, 180 pp.

VV.AA. (1984): «Espacios naturales de la provincia de Alicante». Editado por la Caja de Ahorros Provincial de Alicante y el Colegio Oficial de Arquitectos de Valencia, delegación en Alicante. Alicante, 285 pp. 